Article

\title{
Impact of Germination and Fermentation on Rheological and Thermo-Mechanical Properties of Wheat and Triticale Flours
}

\author{
Iuliana Banu ${ }^{1,+}$, Livia Patraşcu ${ }^{2,+}$, Ina Vasilean ${ }^{1}$, Georgiana Horincar ${ }^{1}$ and Iuliana Aprodu ${ }^{1, * \text { (D) }}$ \\ 1 Faculty of Food Science and Enginnering, Dunarea de Jos University of Galati, 111 Domneasca Str, \\ Galati 800201, Romania; iuliana.banu@ugal.ro (I.B.); ina.vasilean@ugal.ro (I.V.); \\ georgiana.parfene@ugal.ro (G.H.) \\ 2 Cross-Border Faculty, Dunarea de Jos University of Galati, 111 Domneasca Str, Galati 800201, Romania; \\ livia.patrascu@ugal.ro \\ * Correspondence: iuliana.aprodu@ugal.ro \\ + Authors I.B. and L.P contributed equally.
}

Received: 14 October 2020; Accepted: 28 October 2020; Published: 29 October 2020

\begin{abstract}
Common cereal processing through germination and fermentation usually has an important impact on the technological performance of the flours, mainly because of the activation of endogenous enzymes acting on macromolecules. The aim of the present study is to estimate the effect of germination and fermentation, using a mixture of Lactobacillus casei and Kluyveromyces marxianus subsp. marxianus, on the rheological properties of different wheat and triticale varieties. Moreover, the thermo-mechanical behaviour of the white wheat flour-based dough, including germinated grain flour or sourdough was also tested. Grains germination and sourdough fermentation exerted a high influence on the rheological behaviour of the flour-based suspensions. Germination affected the structure and stability of the suspensions, resulting in samples with viscous behaviour prevailing over the elastic one. The temperature ramp tests revealed that germination together with fermentation lead to higher resistance to temperature changes. In agreement with the results of the rheological investigations on rheometer, the Mixolab test performed on flour obtained from germinated grains revealed lower dough stability and protein weakening at temperature increase. On the other hand, a significant improvement of the pasting properties of the dough was obtained when adding sourdoughs to the wheat flour.
\end{abstract}

Keywords: wheat; triticale; sourdough; rheological properties; Mixolab

\section{Introduction}

Bread products obtained from refined wheat flour have relatively poor nutritional value, being low in mineral, vitamin and fibre content [1]. Recently, many studies focused on different processing techniques, aiming to enhance functional properties of wheat flour and quality of the final products. Besides fortification by addition of pseudocereals or leguminous flours to the wheat flour, fermentation and germination were proved to be simple techniques for improving the nutritive and functional properties of grains [2-4]. In particular, Sibian et al. [5] showed that germination improved functional properties of both wheat and triticale flours.

During germination, the main storage biopolymers of cereal grains, namely carbohydrates, proteins and lipids are hydrolysed to lower molecular weight compounds, because of the activity of the hydrolytic enzymes, which are inactive in raw seeds [6]. These processes result in improved digestibility, bioavailability and bioaccessibility of various nutrients and biologically active molecules. In addition, the use of sourdough in bread-making technology leads to increasing levels of numerous 
bioactives [3,4,7-9]. In particular, the mineral bioavailability is improved through the activity of phytate degrading enzymes, which exist in yeast and lactic acid bacteria isolated from sourdough, whereas the digestibility of starch is reduced in the presence of lactic acid produced during sourdough fermentation, resulting in low glycemic index products [1,7].

Both cereal grains germination and sourdough fermentation were reported to significantly influence the technological performance of the flours and doughs. Many studies were focused on the effect of addition of germinated legumes or pseudocereals, such as pea [10], soy [11], broadbean [12], amaranth [6] etc., on the rheological properties of the wheat flour-based dough. Anyway, there are fewer studies regarding the effect of wheat germination and/or fermentation on dough rheology. Singh et al. [13] reported that wheat germination resulted in a softened dough structure, characterized by lower values of the elastic modulus and viscous modulus. A similar effect on the rheological properties caused by sourdough addition to the wheat flour was reported by Clarke et al. [14]. They showed that sourdough addition allowed obtaining more easily extensible doughs. On the other hand, Angioloni et al. [15] reported less elastic and firmer doughs, most probably as a result of physicochemical changes occurring in the protein network induced by the addition of sourdough. The addition of sourdough lowers the $\mathrm{pH}$ of the dough, affecting the structure and properties of different flour components, such as gluten and starch, which influences to a high extent the rheological behaviour of the dough [15].

The aim of the present study is to investigate the impact of the changes induced by wheat and triticale germination and sourdough addition on the rheological properties and thermomechanical behaviour of the dough. In this respect, sourdough samples were obtained through fermentation of the wholemeal flour suspensions using a mixture of lactic acid bacteria and yeast.

\section{Materials and Methods}

\subsection{Materials}

Three wheat cultivars bred in Romania, namely Gabriela $(\mathrm{G})$ and Trivale $(\mathrm{T})$, that are winter type common wheat (Triticum aestivum L.), and spelt (S) (Triticum aestivum subsp. spelta) and one triticale (X Triticosecale Wittmack) cultivar (TT) were used in the study.

The commercial white wheat flour (moisture content of $13.18 \%$, protein content of $9.40 \%$, and ash content of $0.48 \%$ ) was purchased from the local market (Galati, Romania). All chemicals used in the experiment were of analytical grade.

\subsection{Germination of Wheat and Triticale Grain}

The grain samples used in the study were first washed with tap water and then sanitised using aqueous ethanol solution (70\%). After a final rinsing with distilled water, the grains were evenly distributed on sterile cotton layers, moistened and allowed to germinate for four days at $23^{\circ} \mathrm{C} \pm 1$. The germinated Gabriela (gG), Trivale (gT), spelt $(\mathrm{gS})$ and triticale (gTT) samples further used in the experiment were obtained by drying at $55^{\circ} \mathrm{C} \pm 2$ for $48 \mathrm{~h}$ in a convection oven (LabTech LDO-030E, Daihan LabTech Co., LTD, Kyonggi-Do, Korea).

\subsection{Flour Obtaining}

The raw and germinated grain samples were milled with a laboratory mill (WZ-2, Sadkiewicz Instruments, Bydgoszcz, Poland) into flours with particles size lower than $315 \mu \mathrm{m}$. The obtained flours were stored in glass containers at $\sim 4{ }^{\circ} \mathrm{C}$ for further tests. The flour samples obtained by milling the raw grains were used as control for the germination experiment.

\subsection{Proximate Composition}

The proximate composition of the flour samples was determined as follows: the moisture content with the AACC 44-15.02 method [16]; the crude protein content through the Kjeldahl method (AACC 46-11.02; 
Raypa Trade, R. Espinar, S.L., Barcelona, Spain) [16], using a nitrogen conversion factor of 5.83 and ash content using AACC method 08-01 [16].

\subsection{Sourdoughs Preparation}

Inoculum consisted of a mixture of Lactobacillus casei $\left(\mathrm{Nutrish}^{\circledR}\right)$, and yeast Kluyveromyces marxianus subsp. marxianus (LAF4) from Chr Hansen, Brasov, Romania. Producer recommendations were followed to obtain an inoculum size of $10^{8} \mathrm{cfu} / 100 \mathrm{~g}$ sourdough. The fermentation was initiated by mixing the wholemeal flour obtained from raw and germinated grains with tap water and inoculum, such as to get a final dough yield $(100 \times$ mass of dough/mass of flour) of 300 . The fermentation of the sourdoughs was carried out in large beakers covered with aluminium foil at $40{ }^{\circ} \mathrm{C}$ for $20 \mathrm{~h}$, using a laboratory incubator (Pol-Eko Aparatura, Wodzisław Śląski, Poland).

For each type of flour used in the fermentation experiment, a control sample consisting of a flour suspension of the same concentration as in case of sourdoughs preparations, was prepared without inoculum addition.

\subsection{Rheological Properties}

The rheological properties of the control suspensions prepared using flours from raw $(\mathrm{G}, \mathrm{T}, \mathrm{S}$ and $\mathrm{TT})$ or germinated grains (gG, gT, gS and gTT) and of the corresponding sourdough samples (G_SD, T_SD, S_SD and TT_SD prepared out of G, T, S and TT flours, and gG_SD, gT_SD, gS_SD and gTT_SD prepared out of gG, gT, gS and gTT flours) were measured using a controlled-stress rheometer (AR2000ex, TA Instruments, Ltd, New Castle, DE, USA) equipped with a Peltier temperature control system, and a plate-plate geometry (diameter of $40 \mathrm{~mm}$ ). The closing gap was set to $2 \mathrm{~mm}$ and a solvent trap was used to avoid moisture loss during rheological tests.

For each sample the linear viscoelastic region (LVR) yield point was first identified through running stress sweep tests under oscillatory flow in small amplitude conditions, by increasing the stress values from 0.01 to $100 \mathrm{~Pa}$, at an oscillation frequency of $1 \mathrm{~Hz}$. The obtained data were used to determine the stress domain where the structure of the sample remained unaffected, known as the LVR. The intersection of the storage and loss moduli $\left(G^{\prime}\right.$ and $\left.G^{\prime \prime}\right)$, corresponding to the minimal stress value required for the proper beginning of flow, was also estimated [17]. Further dynamic frequency sweep tests were performed within LVR, at a constant oscillatory stress of $0.1 \mathrm{~Pa}$. The working temperature was set at $20^{\circ} \mathrm{C}$ for the stress and frequency sweep tests.

In order to study the structure changes induced by heating in the suspensions and sourdoughs, temperature ramp tests were carried out in quasi-static conditions (frequency of $1 \mathrm{~Hz}$, oscillatory stress of $0.1 \mathrm{~Pa}$ ) by increasing the temperature from 20 to $90^{\circ} \mathrm{C}$ by $1.5^{\circ} \mathrm{C} / \mathrm{min}$. The samples were further maintained at $90^{\circ} \mathrm{C}$ for $10 \mathrm{~min}$. The temperature-induced gelatinization of the studied samples was estimated using the procedure proposed by Ding et al. [18]. The gelatinization temperature range was determined by calculating the first derivative of the third order equation used to fit the $\mathrm{G}^{\prime}$ vs. temperature values, in the area where inflection was observed. Only equations with $\mathrm{r}^{2}$ approaching unity were considered proper for estimating the gelatinization temperature domain.

\subsection{Thermo-Mechanical Properties}

In order to estimate the influence of germination and fermentation processes on the thermo-mechanical properties of the wheat flour-based doughs, the Mixolab Chopin (Tripette \& Renaud Chopin, Villeneuve La Garenne, France) was used.

The impact of germination was determined by performing measurements on mixtures consisting of $15 \%$ wholemeal flour obtained by milling the investigated raw and germinated grains and $85 \%$ white wheat flour. The flours obtained from raw (G, T, S and TT) and germinated (gG, gT, gS and gTT) grains were mixed with the white wheat flour directly into the Mixolab tank.

In the second part of the experiment the white wheat flour (85\%) was supplemented with sourdoughs, prepared with raw and germinated wheat and triticale flours, in such ratio to provide 
the same amount of wholemeal flour $(15 \%)$ as in the case of the first part of the experiment, when the influence of grains germination was tested.

The standard Chopin+ protocol was employed for the empirical rheological measurements, and the typical Mixolab parameters were registered for estimating the properties of the main flour constituents during mixing and thermal treatment. The amount of water added to the mixtures in the Mixolab tank was decided such as to reach the standard torque value of $1.1 \mathrm{Nm}(\mathrm{C} 1)$ at initial mixing. In case of the samples including sourdough, the amount of added water was accordingly reduced. The following torque values were used to gather information on the impact of germination and fermentation on the thermo-mechanical performance of main components of the flours: $\mathrm{C} 2(\mathrm{Nm})$ which is a measure of protein weakening while applying double constraints to the dough, consisting of mechanical work and temperature raise, $\mathrm{C} 3(\mathrm{Nm})$ which gives indication on starch gelatinization, $\mathrm{C} 4(\mathrm{Nm})$ related to the stability of the starch gel at high temperature and $\mathrm{C} 5(\mathrm{Nm})$ which provides evidence on starch retrogradation in the cooling stage. Moreover, the cocking stability (C34) was estimated as the difference between $\mathrm{C} 3$ and $\mathrm{C} 4$.

\subsection{Statistical Analysis}

Two independent germination and fermentation experiments were conducted and the measurements were performed at least in triplicate. The average values are reported together with standard deviations. Analysis of variance (ANOVA) was used to identify significant differences among results. The one-way ANOVA and Tukey's test with a 95\% confidence interval were applied using the Minitab 18 software. Regression analysis was performed to identify any potential relationships between the studied properties of the flour samples.

\section{Results and Discussion}

\subsection{Influence of Germination and Fermentation on the Rheological Properties of Wheat and Triticale Flours}

Wheat and triticale samples were subjected to germination for four days and were then dried to $93.09-93.91 \%$ d.w. The germination process caused a slight increase in the protein content (from $15.04 \%$ to $15.75 \%$ in case of $\mathrm{G}$, from $13.01 \%$ to $13.81 \%$ in case of $\mathrm{T}$, from $12.52 \%$ to $13.80 \%$ in case of $\mathrm{S}$ and from $12.42 \%$ to $12.80 \%$ in case of TT), and had no significant influence on the ash content, which varied between $1.30 \%$ (for G) and $1.73 \%$ (for TT).

Rheological behaviour of flour suspensions and sourdoughs over the oscillatory stress sweep test is presented in Figure 1. Analysing the evolution of the viscoelastic moduli as a function of increasing stress, one can see that, regardless of the germination status, the control samples of all studied grain varieties presented the highest $G^{\prime}$ and $G^{\prime \prime}$ values. A strong solid-like behaviour was noticed for all control samples up to stress values in the 0.7-7.9 Pa range, depending on the flour type. In the LVR, delta values were lower than $24^{\circ}$. Germination affected the structure and stability of the suspension, resulting in formulations having poor rheological quality, with viscous behaviour prevailing over the elastic one. When compared to the raw grains, flour suspensions obtained from germinated samples presented significantly lower values of $G^{\prime}$ and $G^{\prime \prime}$ moduli, with narrower but still present linear viscoelastic regions in case of $\mathrm{G}$ and TT (Figure 1a,d). For the other two germinated wheat varieties, flour suspensions entered directly into the transition phase toward flowing, with rapid decrease of both storage and loss moduli. The control samples yielded much higher stress values in comparison to flour suspensions obtained from the corresponding germinated grains (Table 1). The maximum yield stress value was obtained in the case of $G$ variety, which also presented the highest protein content (15.04\%). Significant correlation was established between protein content and yield stress ( $\mathrm{r}^{2}$ of 0.9009$)$ in case of non-germinated wheat. 

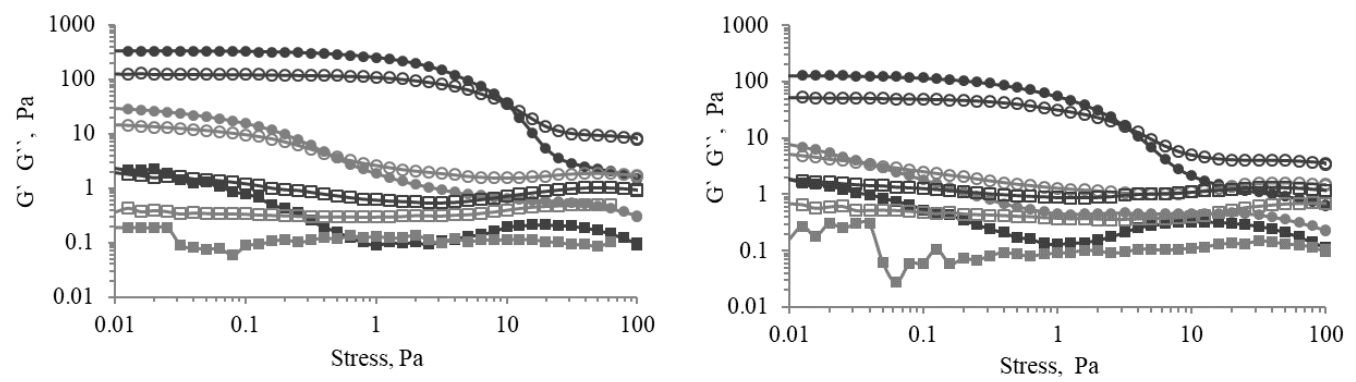

(a)
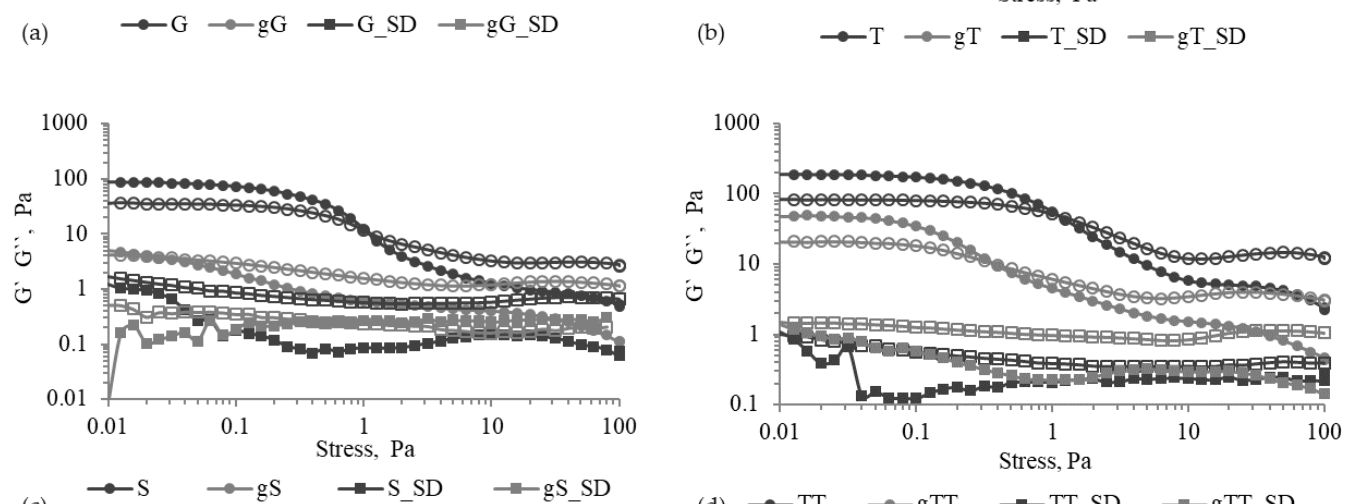

(c)

(d) $\rightarrow$ TT $\rightarrow$ gTT $\rightarrow$ TT_SD $\rightarrow$ gTT_SD

Figure 1. The evolution of the storage and loss moduli $\left(\mathrm{G}^{\prime}\right.$ and $\left.\mathrm{G}^{\prime \prime}\right)$ during the oscillatory stress sweep test for the suspensions and sourdoughs prepared with the wholemeal flours obtained by milling Gabriela (a), Trivale (b), Spelt (c) and Triticale (d) grains. Tests were performed on suspensions prepared using flours from raw (G, T, S and TT) or germinated grains (gG, gT, gS and gTT) and on corresponding sourdough samples (G_SD, T_SD, S_SD and TT_SD prepared out of G, T, S and TT flours and gG_SD, gT_SD, gS_SD and gTT_SD prepared out of gG, gT, gS and gTT flours). Full and open symbols are used for presenting the evolution of $G^{\prime}$ and $G^{\prime \prime}$, respectively.

Table 1. Yield stress, corresponding to the crossover point of storage modulus and loss modulus, for wheat (Gabriela, Trivale, Spelt) and triticale-based suspensions and sourdoughs.

\begin{tabular}{cccc}
\hline \multirow{2}{*}{ Sample } & & \multicolumn{2}{c}{ Yield Stress, Pa } \\
\cline { 3 - 4 } & & Suspension & Sourdough \\
\hline \multirow{2}{*}{ Gabriela } & Raw & $7.96 \pm 4.39$ & $0.03 \pm 0.00$ \\
& Germinated & $0.37 \pm 0.19$ & - \\
Trivale & Raw & $3.78 \pm 0.00$ & - \\
& Germinated & $0.04 \pm 0.00$ & - \\
Spelt & Raw & $0.71 \pm 0.40$ & - \\
& Germinated & $0.02 \pm 0.00$ & - \\
Triticale & Raw & $1.08 \pm 0.16$ & - \\
& Germinated & $0.23 \pm 0.21$ & - \\
\hline
\end{tabular}

The sourdoughs obtained from raw and germinated wheat and triticale samples displayed viscous behaviour $\left(G^{\prime \prime}>G^{\prime}\right)$ from the beginning of the test. Song and Zheng [19] presented the involvement of important molecules from flours, such as starch and gluten proteins, in defining the rheological behaviour of the dough. Among the main components of the flours, starch was shown to exhibit mainly non-linear viscoelastic response [20,21], while gluten was reported to be responsible for dough elasticity, being highly resistant to stress sweep $[17,20]$. Our results indicated that germination and fermentation interfered with gluten performance, most probably as a result of increased protease activity. The decrease of the molecular weight of proteins and peptides, as well as the potential discontinuities in the gluten network caused by the protease assisted cleavage of the peptide bonds affected dough resistance to the applied stress. 
The rheological behaviour of the studied flour suspensions and sourdoughs under temperature constraint is shown in Figure 2. Higher $G^{\prime}$ values were registered for the control samples obtained from raw grain flours at low temperatures, suggesting that the changes occurring in the grains during germination and in the flour matrix during fermentation, affected the rheological stability of the suspensions and sourdoughs.
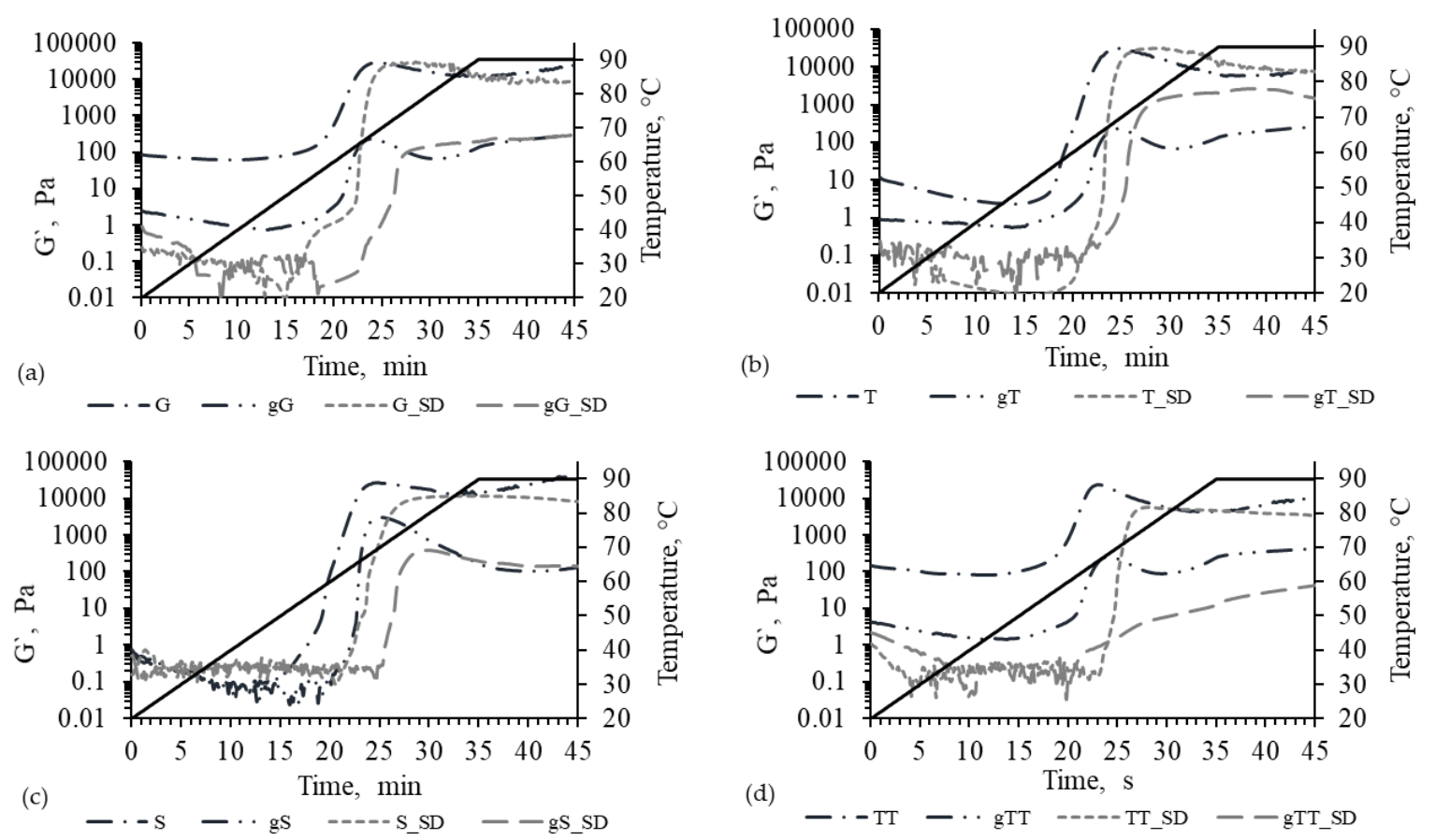

Figure 2. The evolution of the storage modulus of the suspensions and sourdoughs prepared with the wholemeal flours obtained by milling Gabriela (a), Trivale (b), Spelt (c) and Triticale (d) grains, during the temperature ramp test. Tests were performed on suspensions prepared using flours from raw $(\mathrm{G}, \mathrm{T}, \mathrm{S}$ and $\mathrm{TT}$ ) or germinated grains (gG, gT, gS and gTT) and on corresponding sourdough samples (G_SD, T_SD, S_SD and TT_SD prepared out of G, T, S and TT flours, and gG_SD, gT_SD, gS_SD and gTT_SD prepared out of gG, gT, gS and gTT flours). The evolution of the temperature during the rheological test is represented with black full line.

Regardless of the investigated samples, in the first part of the heating stage, a slight decreasing trend of $\mathrm{G}^{\prime}$ was observed (Figure 2). This phenomenon could be associated to the heat-induced weakening of the proteins, and to a lower extent to the starch swelling process which tends to compensate the decrease of $G^{\prime}$ values, caused by gradual proteins weakening. Gänzle et al. [22] stated that degradation of gluten protein structures in sourdoughs affects the viscoelastic properties of the final dough, which explains the lower $G^{\prime}$ values in case of sourdoughs. Except for spelt, at low temperature all sourdough samples had significant lower $G^{\prime}$ values compared to the corresponding suspensions. However, after completion of the gelling process, at $80-90^{\circ} \mathrm{C}$, no significant differences were observed between suspensions and sourdoughs. The curves showing the evolution of the elastic modulus $\left(\mathrm{G}^{\prime}\right)$ were mainly grouped as a function of germination. As a result of the germination process, lower $\mathrm{G}^{\prime}$ values were obtained after achieving the gelling point (Figure 2). This behaviour might be attributed to starch, which competes with proteins for binding the water molecules available in the system. Over the upper limit of protein denaturation temperature range, the starch swelling prevails, further grabbing all available water. Jane et al. [23] stated that the amylose-to-amylopectin ratio highly influences the starch functional properties. Germination was found to increase the amount of amylopectin within starch granules [23,24]. Moreover, the high amount of dextrose and maltose formed through starch hydrolysis during germination as a result of increased amylolytic activity will interfere with gel formation. In this respect, Chinma et al. [25] observed that germination determined the increase of the least gelling 
concentration of Cyperus esculentus flours from 12 to $20 \%$. Therefore, higher dosage of germinated flour is needed to achieve a dough consistency similar to the non-germinated wheat flour.

In order to study the temperature-induced gelatinization of the suspensions and sourdoughs, the experimental results in the inflexion area of $G^{\prime}$ vs. temperature curves (Figure 2) were fitted using a third-order equation, and the gelatinization temperature domains were estimated by calculating the first derivative of these equations. Analysing the results presented in Figure 3 one can observe that germination together with fermentation determined the increase of the gelatinization temperature domains. Our results comply with Frias et al. [24], who showed that germination altered lentil starch granule surface, leading to higher resistance to temperature changes.

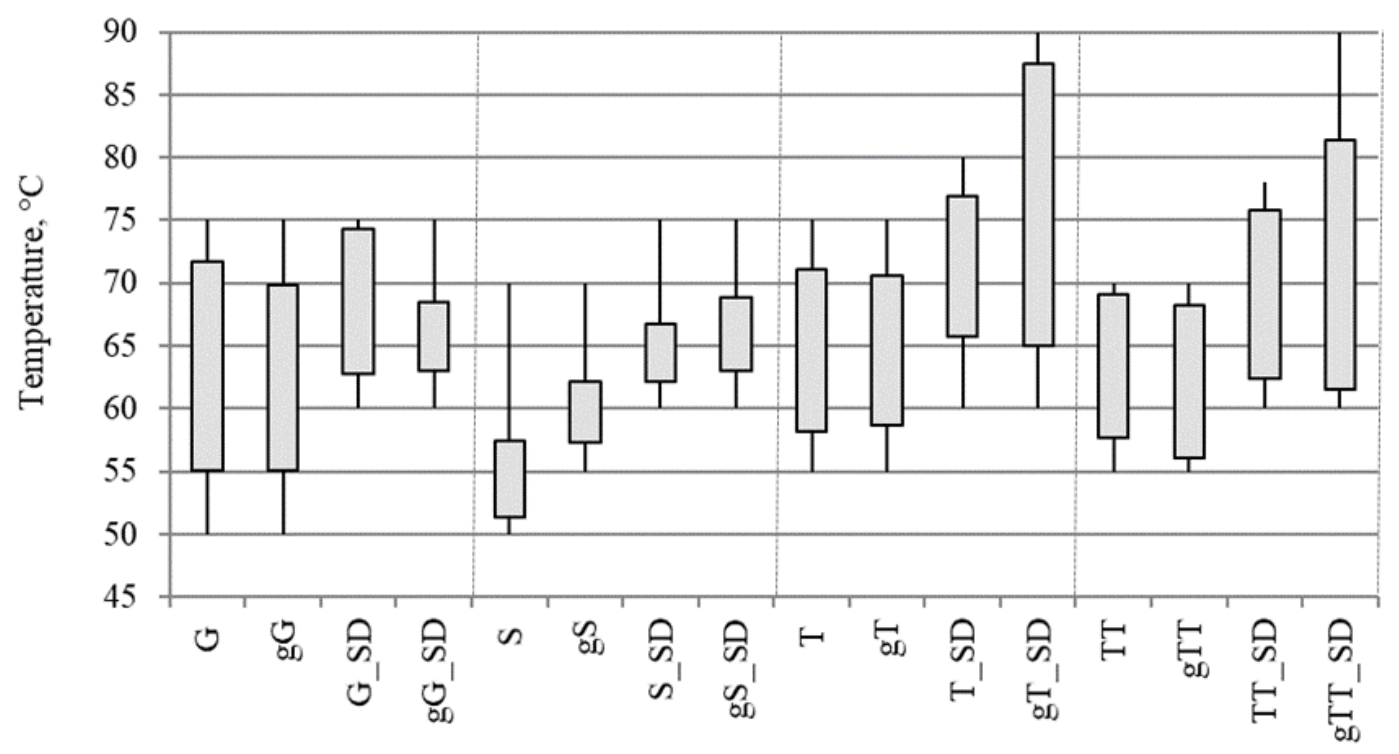

Figure 3. Temperature domains corresponding to the gelling process for the studied suspensions and sourdoughs during the temperature ramp test. The analysed temperature ranges corresponding to the inflection area of $G^{\prime}$ vs. $t$ curves are represented with lines, whereas the estimated gelling temperature domains are indicated as columns. Tests were performed on suspensions prepared using flours from raw $(\mathrm{G}, \mathrm{T}, \mathrm{S}$ and $\mathrm{TT})$ or germinated grains (gG, gT, gS and gTT) and on corresponding sourdough samples (G_SD, T_SD, S_SD and TT_SD prepared out of G, T, S and TT flours, and gG_SD, gT_SD, gS_SD and gTT_SD prepared out of gG, gT, gS and gTT flours).

\subsection{Influence of Germination and Fermentation on the Thermo-Mechanical Properties of Doughs}

The impact of grains germination and sourdough fermentation on the bread making properties of the white wheat flour, was estimated by monitoring the thermo-mechanical behaviour of the doughs by means of Mixolab device. The main Mixolab parameters registered when supplementing the white wheat flour with $15 \%$ wholemeal flours from raw or grains or corresponding sourdoughs are presented in Table 2.

\subsubsection{Influence of Grain Germination}

The addition of $15 \%$ wholemeal flour obtained through grinding the germinated G, T, S and TT grain samples to the white wheat flour resulted in significant shortening of dough stability (DS) compared to the corresponding raw samples. The DS values ranged from 8.82 to $9.93 \mathrm{~min}$ in case of the doughs prepared with raw grain flour, and from 2.68 to $4.03 \mathrm{~min}$ for the samples with germinated grain flour (Table 2). Our results are in agreement with Rosales-Juarez et al. [11] who tested the influence of germinated and non-germinated soybean flour on the rheological behaviour of the doughs and, regardless of the addition level, reported shorter stability of the wheat flour-based dough samples supplemented with germinated soy flour. On the other hand, Sadowska et al. [10] reported dough 
stability prolongation for the wheat flour-based samples, including different percentages of germinated pea flour, compared to the samples with raw pea flour. When the dough was subjected to the dual constraint of mechanical shear and temperature, the consistency decreased to a minimum torque (C2) varying with the flour mixture and type of processing (Table 2). Higher $\mathrm{C} 2$ values were registered for dough samples with raw grain flour addition $(0.42-0.47 \mathrm{Nm})$, compared to the samples prepared with corresponding germinated grain flour $(0.12-0.17 \mathrm{Nm})$. The decrease of both $\mathrm{C} 2$ and DS values observed when testing flour from germinated grains, can be explained by the advanced disruption of the protein network caused by peptidase formed during germination. The protein aggregates stabilised through the disulfide or dityrosine linking and hydrogen bonds are essentially responsible for dough consistency and stability [26]. According to Bigiarini et al. [27], gliadins are degraded during germination into small peptides, the enzymes mainly responsible for this activity being cysteine proteinase and carboxypeptidases, which are highly active during wheat germination.

Table 2. Effect of the addition of flours from raw (G, T, $\mathrm{S}$ and TT) or germinated grains ( $\mathrm{gG}, \mathrm{gT}$, gS and gTT) and of corresponding sourdough samples (G_SD, T_SD, S_SD and TT_SD prepared out of G, T, S and TT flours, and gG_SD, gT_SD, gS_SD and gTT_SD prepared out of gG, gT, gS and gTT flours). On the thermo-mechanical properties of the white wheat flour (WF) dough. Measurements were performed in triplicate by means of Mixolab using the Chopin+ protocol.

\begin{tabular}{cccccc}
\hline Samples & DS, min & C2, Nm & C3, Nm & C4, Nm & C5, Nm \\
\hline WF + G & $9.93 \pm 0.12^{\mathrm{a}}$ & $0.46 \pm 0.01^{\mathrm{a}}$ & $1.99 \pm 0.01^{\mathrm{a}}$ & $1.76 \pm 0.01^{\mathrm{a}}$ & $2.64 \pm 0.02^{\mathrm{a}}$ \\
WF + gG & $3.23 \pm 0.10^{\mathrm{c}}$ & $0.17 \pm 0.01^{\mathrm{c}}$ & $0.51 \pm 0.01^{\mathrm{c}}$ & $0.05 \pm 0.00^{\mathrm{c}}$ & $0.02 \pm 0.00^{\mathrm{c}}$ \\
WF + G_SD & $5.42 \pm 0.10^{\mathrm{b}}$ & $0.31 \pm 0.01^{\mathrm{b}}$ & $1.85 \pm 0.01^{\mathrm{b}}$ & $1.74 \pm 0.01^{\mathrm{a}}$ & $2.64 \pm 0.01^{\mathrm{a}}$ \\
WF + Gg_SD & $5.32 \pm 0.10^{\mathrm{b}}$ & $0.12 \pm 0.01^{\mathrm{d}}$ & $0.40 \pm 0.01^{\mathrm{d}}$ & $0.35 \pm 0.01^{\mathrm{b}}$ & $1.09 \pm 0.02^{\mathrm{b}}$ \\
\hline WF + T & $8.83 \pm 0.09^{\mathrm{a}}$ & $0.47 \pm 0.01^{\mathrm{a}}$ & $2.20 \pm 0.01^{\mathrm{a}}$ & $1.88 \pm 0.01^{\mathrm{a}}$ & $2.83 \pm 0.01^{\mathrm{a}}$ \\
WF + gT & $2.68 \pm 0.10^{\mathrm{d}}$ & $0.16 \pm 0.01^{\mathrm{c}}$ & $0.42 \pm 0.01^{\mathrm{d}}$ & $0.03 \pm 0.00^{\mathrm{d}}$ & $0.01 \pm 0.00^{\mathrm{d}}$ \\
WF + T_SD & $5.23 \pm 0.11^{\mathrm{b}}$ & $0.32 \pm 0.01^{\mathrm{b}}$ & $1.82 \pm 0.01^{\mathrm{b}}$ & $1.65 \pm 0.01^{\mathrm{b}}$ & $2.56 \pm 0.02^{\mathrm{b}}$ \\
WF + Tg_SD & $4.68 \pm 0.10^{\mathrm{c}}$ & $0.12 \pm 0.01^{\mathrm{d}}$ & $0.55 \pm 0.01^{\mathrm{c}}$ & $0.18 \pm 0.01^{\mathrm{c}}$ & $0.18 \pm 0.01^{\mathrm{c}}$ \\
\hline WF + S & $9.33 \pm 0.10^{\mathrm{a}}$ & $0.43 \pm 0.01^{\mathrm{a}}$ & $1.88 \pm 0.01^{\mathrm{a}}$ & $1.52 \pm 0.01^{\mathrm{b}}$ & $2.26 \pm 0.02^{\mathrm{b}}$ \\
WF + gS & $4.03 \pm 0.11^{\mathrm{d}}$ & $0.14 \pm 0.01^{\mathrm{c}}$ & $0.94 \pm 0.01^{\mathrm{c}}$ & $0.26 \pm 0.01^{\mathrm{d}}$ & $0.32 \pm 0.01^{\mathrm{d}}$ \\
WF + S_SD & $6.10 \pm 0.09^{\mathrm{b}}$ & $0.37 \pm 0.01^{\mathrm{b}}$ & $1.84 \pm 0.01^{\mathrm{b}}$ & $1.80 \pm 0.01^{\mathrm{a}}$ & $2.72 \pm 0.02^{\mathrm{a}}$ \\
WF + Sg_SD & $4.83 \pm 0.09^{\mathrm{c}}$ & $0.12 \pm 0.01^{\mathrm{c}}$ & $0.96 \pm 0.01^{\mathrm{c}}$ & $0.53 \pm 0.01^{\mathrm{c}}$ & $0.75 \pm 0.01^{\mathrm{c}}$ \\
\hline WF + TT & $8.82 \pm 0.11^{\mathrm{a}}$ & $0.42 \pm 0.01^{\mathrm{a}}$ & $1.84 \pm 0.01^{\mathrm{a}}$ & $1.33 \pm 0.01^{\mathrm{b}}$ & $2.00 \pm 0.02^{\mathrm{b}}$ \\
WF + gTT & $3.12 \pm 0.09^{\mathrm{d}}$ & $0.12 \pm 0.01^{\mathrm{c}}$ & $0.31 \pm 0.01^{\mathrm{c}}$ & $0.01 \pm 0.00^{\mathrm{d}}$ & $0.00 \pm 0.00^{\mathrm{d}}$ \\
WF + TT_SD & $6.32 \pm 0.10^{\mathrm{b}}$ & $0.33 \pm 0.01^{\mathrm{b}}$ & $1.77 \pm 0.01^{\mathrm{b}}$ & $1.50 \pm 0.01^{\mathrm{a}}$ & $2.25 \pm 0.02^{\mathrm{a}}$ \\
WF + TTg_SD & $5.32 \pm 0.12^{\mathrm{c}}$ & $0.09 \pm 0.01^{\mathrm{d}}$ & $0.29 \pm 0.01^{\mathrm{c}}$ & $0.06 \pm 0.00^{\mathrm{c}}$ & $0.10 \pm 0.00^{\mathrm{c}}$ \\
\hline a-d average values in columns signed by the same superscript letter are not statistically different $(p=95 \%)$.
\end{tabular}

As shown in Table 2 and Figure 4, the use of gG, gT, gS and gTT flours resulted in changes of the pasting properties compared to the corresponding dough samples with raw $G, T, S$ and TT flour (controls). It should be noted that addition of raw TT and S flour had a higher influence on pasting properties compared to $\mathrm{G}$ and $\mathrm{T}$. The highest values of the maximum torque during heating (C3) were 1.99 and $2.20 \mathrm{Nm}$ in case of the samples with raw $\mathrm{G}$ and $\mathrm{T}$ flour addition. Weaker starch gel stability (C4) was registered for dough samples with $\mathrm{S}$ and TT, most probably because of the high amylase activity in these samples, compared to $G$ and T. Triticale and spelt tend to have higher $\alpha$-amylase activity compared to wheat, depending on the cropping environment [28,29].

Different tendency of the Mixolab curves was registered when germinated grain flours were added to the white flour to obtain dough samples (Figure $4 \mathrm{~b}$ ). Germination induced the increase of amylase activity and consequently starch hydrolysis became very evident after the gelatinization. Therefore, significantly lower $\mathrm{C} 4$ values were registered for the dough samples including germinated grain flours. The cooking stability (C34) ranged from $0.3 \mathrm{Nm}$ to $0.68 \mathrm{Nm}$, suggesting that the amylase activity continued even during the Chopin+ stage when the dough is heated at $90{ }^{\circ} \mathrm{C}$. According to 
Dubat and Boinot [30], the (C34) values increased from $0.11 \mathrm{Nm}$ to $0.46 \mathrm{Nm}$ when adding exogenous maltogenic amylases to the wheat flour. Similar reduction was observed for the torque values, which gives indication about starch retrogradation (C5). When studying the influence of brown rice and soy germination on the bread-making performance of the flours, Cornejo and Rosell [31] and Patraşcu et al. [32] registered lower torque values while heating the dough up to $90^{\circ} \mathrm{C}$ and at further cooling down to $50^{\circ} \mathrm{C}$. They explained this change in the thermo-mechanical behaviour of the dough through the extensive hydrolysis of the starch by the amylases-activated during germination.

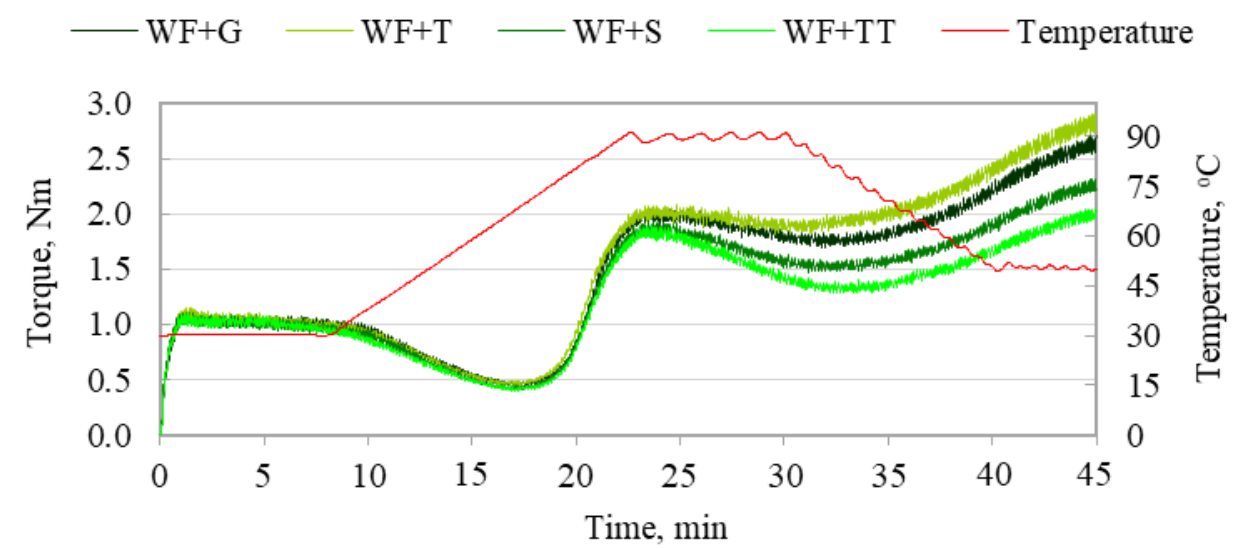

(a)

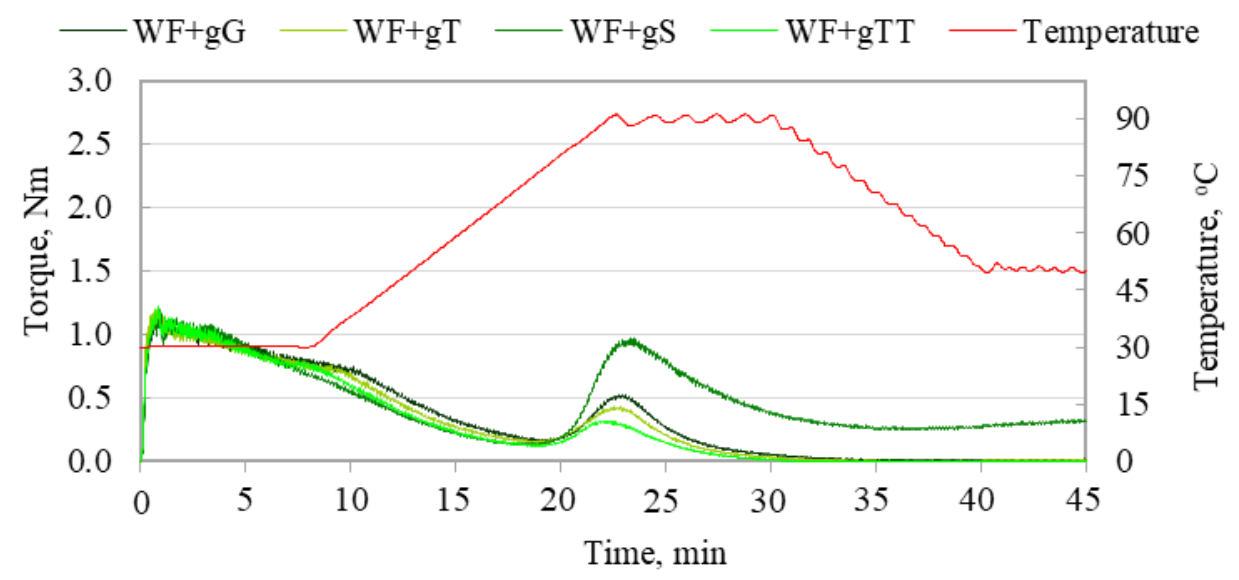

(b)

Figure 4. Mixolab curves of the white wheat flour (WF) supplemented with $15 \%$ wholemeal flours obtained by milling (a) raw (G, T, S and TT) and (b) germinated grains (gG, gT, gS and gTT).

\subsubsection{Influence of Sourdough Addition}

Regardless of the investigated grain sample, the addition of sourdoughs prepared with raw grain flours (G_SD, T_SD, S_SD and TT_SD) resulted in doughs with lower DS and C2 values (Table 2). The sourdough fermentation caused the DS shortening from 8.82-9.93 $\mathrm{min}$ to 5.23-6.32 $\mathrm{min}$, and the C2 diminishing from $0.42-0.47 \mathrm{Nm}$ to $0.31-0.37 \mathrm{Nm}$. On the other hand, the addition of sourdough prepared with germinated grain flour resulted in higher DS and lower C2 values compared to the corresponding samples with raw grain flour. This trend registered for the dough samples including sourdoughs might be the result of the low $\mathrm{pH}$ value. In agreement with Bottari et al. [33], the optimal $\mathrm{pH}$ for gliadin hydrolysis is 4.25. Moreover, Banu and Aprodu [26] and Clarke et al. [34] showed that dough behaviour during mixing at $30{ }^{\circ} \mathrm{C}$ and during temperature increase from 30 to $55-60{ }^{\circ} \mathrm{C}$ is influenced by $\mathrm{pH}$, affecting both DS and $\mathrm{C} 2$ values. Similar results for DS and C2 were obtained when preparing dough with raw and germinated soybean flour added to the wheat flour [32]. The authors 
explained the reduction of $\mathrm{C} 2$ values by protein weakening during dough mixing and heating by $4{ }^{\circ} \mathrm{C} / \mathrm{min}$, but also by the action of proteolytic enzymes that are activated during germination.

The dough samples prepared with sourdoughs made of raw G, S and T flours displayed similar pasting properties, the torque values being significantly higher with respect to the TT-based sample (Figure 5). For instance, the values of C5 that defines starch retrogradation, ranged from $2.25 \mathrm{Nm}$, corresponding to the sample with TT-based sourdough, to $2.72 \mathrm{Nm}$ in case of the sample with S, suggesting different optimal end-use for each sample. According to Dubat and Boinot [30] the flours suitable for bread making, brioche and biscuits have $\mathrm{C} 5$ of $2.05,2.43$ and $2.75 \mathrm{Nm}$, respectively.

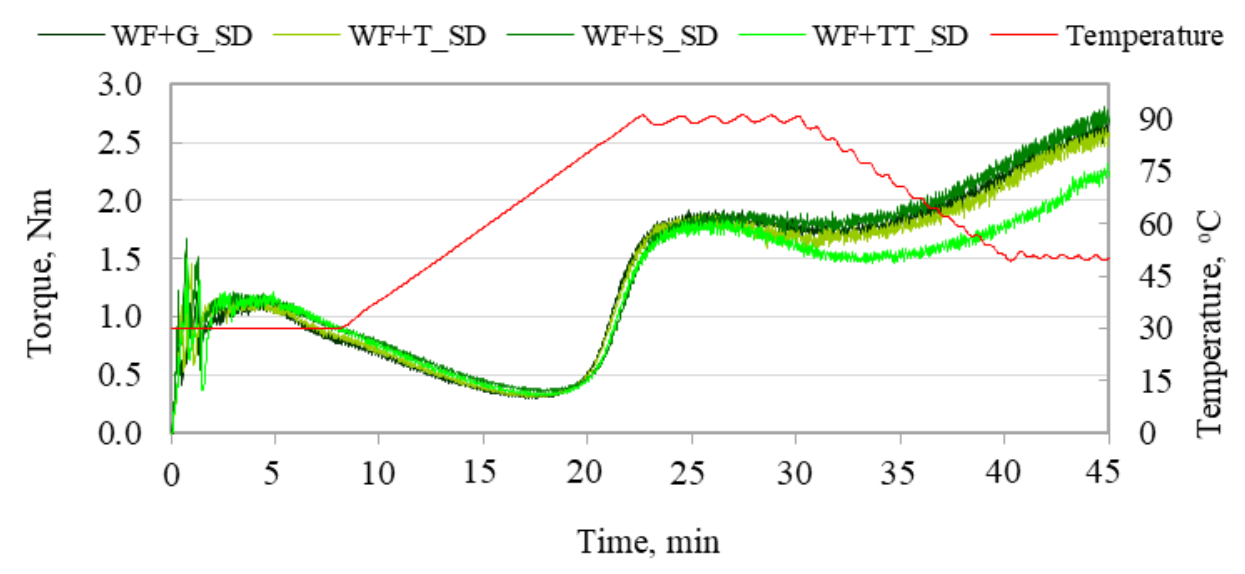

(a)

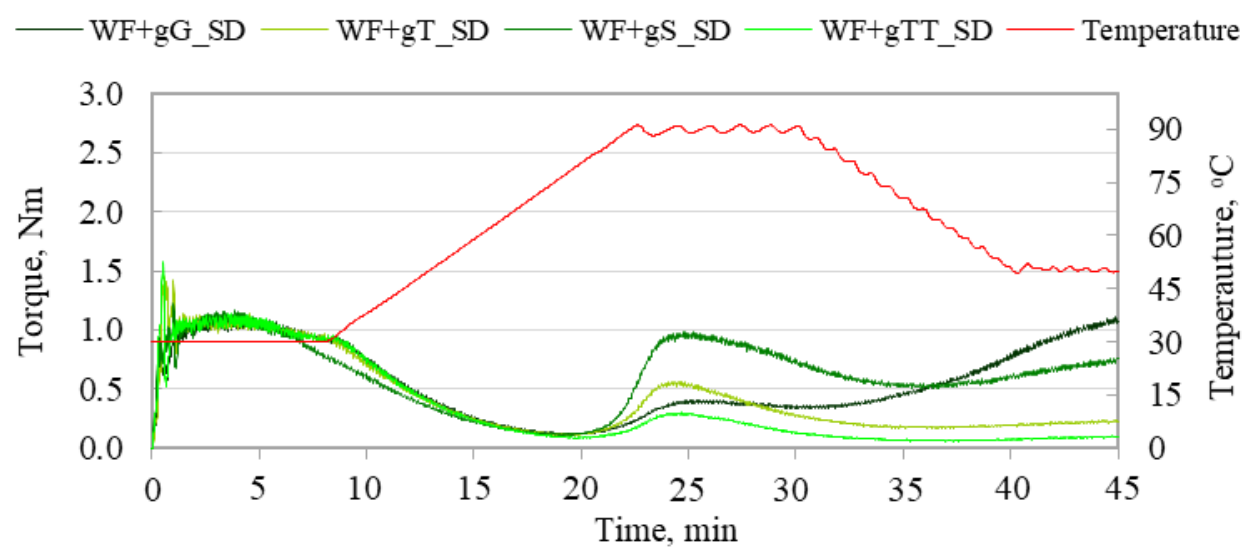

(b)

Figure 5. Mixolab curves of the white wheat flour (WF) supplemented with sourdoughs prepared with flours from (a) raw (G_SD, T_SD, S_SD and TT_SD) and (b) germinated grains (gG_SD, gT_SD, gS_SD and gTT_SD).

Grains germination improved starch gelatinization, starch stability and starch retrogradation properties of the dough samples prepared with sourdough (Table 2). The decrease of the $\mathrm{pH}$ during sourdough fermentation limited the activity of $\alpha$-amylase, and consequently improved starch stability. The most significant improvement of the pasting properties was observed in case of the dough sample including sourdough prepared with germinated G flour.

\section{Conclusions}

Processing wheat and triticale through germination and further sourdough fermentation affected the rheological and thermo-mechanical properties of the flours. Regardless of the investigated grain, a narrower viscoelastic domain was obtained for samples subjected to germination and/or fermentation. The partial hydrolysis of the starch and proteins during germination as a result of 
increased hydrolytic activity of the enzymes interfered with gel formation at thermal treatment. The rheological tests indicated that combining grains germination and sourdough fermentation results in increased gelatinization temperature domains. The addition of $15 \%$ flour obtained from germinated wheat or triticale significantly affected protein weakening, starch gelatinization, the stability of the starch gel at high temperature and starch retrogradation, causing significant shortening of dough stability.

Author Contributions: Conceptualisation, I.A. and I.B.; methodology, L.P. and I.B.; software, I.A., L.P. and I.B.; validation, I.V. and G.H.; formal analysis, L.P., I.B. and I.A.; investigation, I.B., L.P., I.V. and G.H.; resources, I.A. and G.H.; writing —original draft preparation, I.B. and L.P.; writing—review and editing, I.A.; supervision, I.A.; project administration, I.A.; funding acquisition, I.A. and G.H. All authors have read and agreed to the published version of the manuscript.

Funding: This work was funded by a grant of the Romanian National Authority for Scientific Research and Innovation, CNCS-UEFISCDI, project number PN-II-RU-TE-2014-4-0618.

Acknowledgments: This work was supported by the project "EXPERT", financed by the Romanian Ministry of Research and Innovation, Contract no. 14PFE/17.10.2018. The Integrated Center for Research, Expertise, and Technological Transfer in Food Industry is acknowledged for providing technical support.

Conflicts of Interest: The authors declare no conflict of interest.

\section{References}

1. Dewettinck, K.; Van Bockstaele, F.; Kühne, B.; Van de Walle, D.; Courtens, T.M.; Gellynck, X. Nutritional value of bread: Influence of processing, food interaction and consumer perception. J. Cereal Sci. 2008, 48, $243-257$. [CrossRef]

2. Katina, K.; Liukkonen, K.H.; Kaukovirta-Norja, A.; Adlercreutz, H.; Heinonen, S.M.; Lampi, A.M.; Pihlava, J.-M.; Poutanen, K. Fermentation-induced changes in the nutritional value of native or germinated rye. J. Cereal Sci. 2007, 46, 348-355. [CrossRef]

3. Banu, I.; Vasilean, I.; Aprodu, I. Effect of lactic fermentation on antioxidant capacity of rye sourdough and bread. Food Sci. Technol. Res. 2010, 16, 571-576. [CrossRef]

4. Patrascu, L.; Vasilean, I.; Turtoi, M.; Garnai, M.; Aprodu, I. Pulse germination as tool for modulating their functionality in wheat flour sourdoughs. Qual. Assur. Saf. Crop. 2019, 11, 269-282. [CrossRef]

5. Sibian, M.S.; Saxena, D.C.; Riar, C.S. Effect of germination on chemical, functional and nutritional characteristics of wheat, brown rice and triticale: A comparative study. J. Sci. Food Agric. 2017, 97, 4643-4651. [CrossRef] [PubMed]

6. Guardianelli, L.M.; Salinas, M.V.; Puppo, M.C. Hydration and rheological properties of amaranth-wheat flour dough: Influence of germination of amaranth seeds. Food Hydrocoll. 2019, 97, 105242. [CrossRef]

7. Katina, K.; Arendt, E.; Liukkonen, K.H.; Autio, K.; Flander, L.; Poutanen, K. Potential of sourdough for healthier cereal products. Trends Food Sci. Technol. 2005, 16, 104-112. [CrossRef]

8. Gobbetti, M.; De Angelis, M.; Di Cagno, R.; Calasso, M.; Archetti, G.; Rizzello, C.G. Novel insights on the functional/nutritional features of the sourdough fermentation. Int. J. Food Microbiol. 2019, 302, 103-113. [CrossRef]

9. Gobbetti, M.; De Angelis, M.; Di Cagno, R.; Polo, A.; Rizzello, C.G. The sourdough fermentation is the powerful process to exploit the potential of legumes, pseudo-cereals and milling by-products in baking industry. Crit. Rev. Food Sci. 2020, 60, 2158-2173. [CrossRef]

10. Sadowska, J.; Blaszczak, W.; Fornal, J.; Vidal-Valverde, C.; Frias, J. Changes of wheat dough and bread quality and structure as a result of germinated pea flour addition. Eur. Food Res. Technol. 2003, 216, 46-50. [CrossRef]

11. Rosales-Juarez, M.; Gonzalez-Mendoza, B.; Lopez-Guel, E.C.; Lozano-Bautista, F.; Chanona-Perez, J.; Gutierrez-Lopez, G.; Farrera-Rebollo, R.; Calderon-Domínguez, G. Changes on dough rheological characteristics and bread quality as a result of the addition of germinated and non-germinated soybean flour. Food Bioprocess Technol. 2008, 1, 152-160. [CrossRef]

12. Aprodu, I.; Vasilean, I.; Muntenită, C.; Patrascu, L. Impact of broad beans addition on rheological and thermal properties of wheat flour based sourdoughs. Food Chem. 2019, 293, 520-528. [CrossRef] [PubMed]

13. Singh, H.; Singh, N.; Kaur, L.; Saxena, S.K. Effect of sprouting conditions on functional and dynamic rheological properties of wheat. J. Food Eng. 2001, 47, 23-29. [CrossRef] 
14. Clarke, C.I.; Schober, T.J.; Arendt, E.K. Effect of single strain and traditional mixed strain starter cultures on rheological properties of wheat dough and on bread quality. Cereal Chem. 2002, 79, 640-647. [CrossRef]

15. Angioloni, A.; Romani, S.; Pinnavaia, G.G.; Dalla Rosa, M. Characteristics of bread making doughs: Influence of sourdough fermentation on the fundamental rheological properties. Eur. Food Res. Technol. 2006, 222, 54-57. [CrossRef]

16. AACC International. Approved Methods of Analysis, 11th ed.; Methods 44-15.02, 46-11.02, 08-01; American Association of Cereal Chemists International: St. Paul, MN, USA, 2000.

17. Patraşcu, L.; Banu, I.; Vasilean, I.; Aprodu, I. Effect of gluten, egg and soy proteins on the rheological and thermo-mechanical properties of wholegrain rice flour. Food Sci. Technol. Int. 2016, 23, 142-155. [CrossRef] [PubMed]

18. Ding, Y.; Liu, R.; Rong, J.; Liu, Y.; Zhao, S.; Xiong, S. Rheological behavior of heat-induced actomyosin gels from yellowcheek carp and grass carp. Eur. Food Res. Technol. 2012, 235, 245-251. [CrossRef]

19. Song, Y.; Zheng, Q. Dynamic rheological properties of wheat flour dough and proteins. Trends Food Sci. Technol. 2007, 18, 132-138. [CrossRef]

20. Khatkar, B.S.; Fido, R.J.; Tatham, A.S.; Schofield, J.D. Functional properties of wheat gliadins. II. Effects on dynamic rheological properties of wheat gluten. J. Cereal Sci. 2002, 35, 307-313. [CrossRef]

21. Patraşcu, L.; Banu, I.; Vasilean, I.; Aprodu, I. Rheological and thermo-mechanical characterization of starch-Protein mixtures. Agric. Agric. Sci. Proc. 2016, 10, 280-288. [CrossRef]

22. Gänzle, M.G.; Loponen, J.; Gobbetti, M. Proteolysis in sourdough fermentations: Mechanisms and potential for improved bread quality. Trends Food Sci. Technol. 2008, 19, 513-521. [CrossRef]

23. Jane, J.; Chen, Y.Y.; Lee, L.F.; McPherson, A.E.; Wong, K.S.; Radosavljevic, M.; Kasemsuwan, T. Effects of amylopectin branch chain length and amylose content on the gelatinization and pasting properties of starch 1. Cereal Chem. 1999, 76, 629-637. [CrossRef]

24. Frias, J.; Fornal, J.; Ring, S.G.; Vidal-Valverde, C. Effect of germination on physico-chemical properties of lentil starch and its components. LWT Food Sci. Technol. 1998, 31, 228-236. [CrossRef]

25. Chinma, C.E.; Adewuyi, O.; Abu, J.O. Effect of germination on the chemical, functional and pasting properties of flour from brown and yellow varieties of tigernut (Cyperus esculentus). Food Res. Int. 2009, 4, 1004-1009. [CrossRef]

26. Banu, I.; Aprodu, I. Studies concerning the use of Lactobacillus helveticus and Kluyveromyces marxianus for rye sourdough fermentation. Eur. Food Res. Technol. 2012, 234, 769-777. [CrossRef]

27. Bigiarini, L.; Pieri, N.; Grilli, I.; Galleschi, L.; Capocchi, A.; Fontanini, D. Hydrolysis of gliadin during germination of wheat seeds. J. Plant Physiol. 1995, 147, 161-167. [CrossRef]

28. Hidalgo, A.; Brusco, M.; Plizzari, L.; Brandolini, A. Polyphenol oxidase, alpha-amylase and beta-amylase activities of Triticum monococcum, Triticum turgidum and Triticum aestivum: A two-year study. J. Cereal Sci. 2013, 58, 51-58. [CrossRef]

29. Zhu, F. Triticale: Nutritional composition and food uses. Food Chem. 2018, 241, 468-479. [CrossRef]

30. Dubat, A.; Boinot, N. Mixolab Applications Handbook. In Rheological and Enzymes Analyses; Chopin Technology: Villenueve, France, 2012; pp. 10-15, 114-115.

31. Cornejo, F.; Rosell, C.M. Influence of germination time of brown rice in relation to flour and gluten free bread quality. J. Food Sci. Technol. 2015, 52, 6591-6598. [CrossRef]

32. Patraşcu, L.; Banu, I.; Vasilean, I.; Aprodu, I. Effects of germination and fermentation on the functionality of whole soy flour. Bull. USAMV Sci. Biotechnol. 2016, 73, 126-134. [CrossRef]

33. Bottari, A.; Capocchi, A.; Fontanini, D.; Galleschi, L. Major proteinase hydrolyzing gliadin during wheat germination. Phytochem 1996, 43, 39-44. [CrossRef]

34. Clarke, C.I.; Schober, T.J.; Angst, E.; Arendt, E.K. Use of response surface methodology to investigate the effects of processing conditions on sourdough wheat bread quality. Eur. Food Res. Technol. 2003, 217, $23-33$.

Publisher's Note: MDPI stays neutral with regard to jurisdictional claims in published maps and institutional affiliations. 